\title{
Fine Particle Emission from Diesel and Gasoline Vehicles at Constant and Transient Conditions
}

\author{
Martin Mohr, Christian Bach \\ Swiss Federal Laboratories for Materials Testing and Research (EMPA) \\ Section I.C. Engines/Fumaces \\ Überlandstrasse 129, CH 8600 Dübendorf, Switzerland
}

\begin{abstract}
KEYWORDS
automotive exhaust particles, time-resolved particle sizing, number size distribution
\end{abstract}

It is well known that exhaust gas from diesel engines includes a significant amount of respirable particulates. The particles comprise of a solid core of unburned carbon which is coated with organic and inorganic condensates (Steiner and Burtscher, 1993). Due to their small size they penetrate deeply into the human respiratory tract and can have a negative effect on the human health. On the other hand, gasoline fuelled vehicles are considered to produce generally very low particle emissions based on mass measurements. However, there are still some open questions about the particle emission of gasoline cars:

- How is the particle emission based on number concentration?

- How is the particle emission affected by the driving conditions?

- What is the composition of the particles?

In this study the particulate emissions of diesel and gasoline passenger cars were determined and compared in the submicron size range at constant and transient loads. Particle number size distributions were measured using a Differential Mobility Analyser (DMA) and a Condensation Particle Counter (CPC) (Knutson and Whitby, 1975). For particle sampling a standard particle dilution tunnel (CVS) was used in the experiments. The motor vehicles were tested on a single $1500 \mathrm{~mm}$ roll chassis dynamometer at four constant velocities and using the European driving cycle (ECE+EUDC). The details of the test schedule is shown in Table 1. The cars run on gasoline were equipped with a standard three-way catalyst. At the steady state tests the vehicles and tunnel were preconditioned until a stable oil temperature, catalyst temperature and tunnel temperature were reached. All driving cycle tests were performed with cold engines. Since the SMPS cannot provide full size distributions at transient conditions the total particle number and the particles number in several discrete particle size classes between $25 \mathrm{~nm}$ and $600 \mathrm{~nm}$ were monitored by repeating the test procedure. The composition of the particles were determined by extraction with dichloromethane to distinguish the organic soluble (SOF) from the insoluble (INSOF) particle mass fraction. The amount of SOF was calculated as filter weight difference before and after the Soxhlet extraction.

Table 1. Details of the test schedule

\begin{tabular}{lccc}
\hline & Speed & Gear & Preconditioning \\
\hline steady state & $50 \mathrm{~km} / \mathrm{h}$ & 3 & warm \\
steady state & $80 \mathrm{~km} / \mathrm{h}$ & 5 & warm \\
steady state & $120 \mathrm{~km} / \mathrm{h}$ & 5 & warm \\
steady state & $80 \mathrm{~km} / \mathrm{h} \mathrm{full-load}$ & 5 & warm \\
driving cycle: ECE+EUDC & $0-120 \mathrm{~km} / \mathrm{h}$ & $1-5$ & cold engine start \\
\hline
\end{tabular}




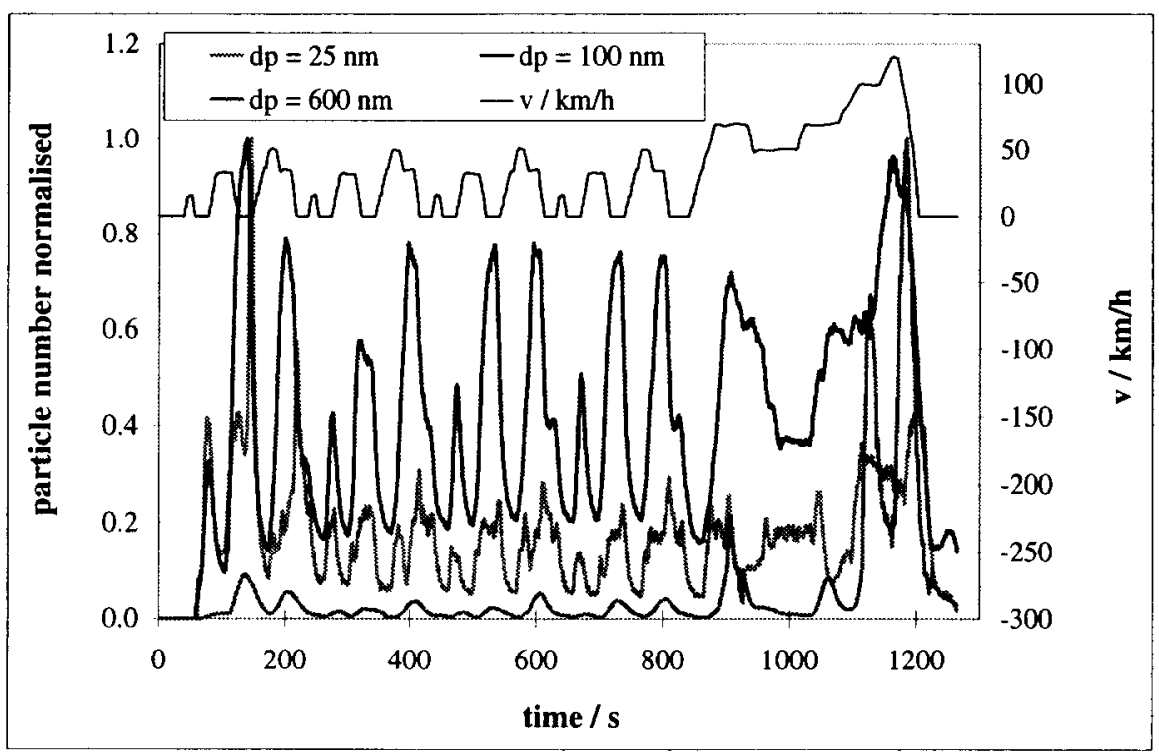

Figure 1. Particle emission vs. time of a diesel car for three narrow size channels during a cold ECE+EUDC

The diesel vehicles produced a significant higher number of particles at all tested driving conditions than gasoline fuelled cars. At the steady state experiments the gasoline cars showed increased emissions at high loads. However, the total particle concentrations were still more than one order of magnitude below the values of the diesel cars. The mode of the distributions was in the range of $70 \mathrm{~nm}$ to $90 \mathrm{~nm}$ for the gasoline vehicle and between $80 \mathrm{~nm}$ and $110 \mathrm{~nm}$ for the diesel vehicle. Only for the diesel cars a slight shift to larger particles sizes was observed with increasing load. The chemical analysis of the particles results in about $80 \%$ SOF for the gasoline car and about $20 \%$ for the diesel car at high loads.

Figure 1 shows results of the transient tests with the diesel car. The normalised number of particles emitted vs. time is presented for three small size channels. It can be seen that very small particles $\left(d_{p}=25 \mathrm{~nm}\right)$ were mainly produced in the cold start period, whereas most of the large particles $\left(d_{p}=600 \mathrm{~nm}\right)$ were exhausted at the highest load. Particles of $100 \mathrm{~nm}$ diameter, which were dominant in absolute scale during the entire cycle, wcre weakly affected by the cold start and the highest load, but show a clear correlation with the speed and accelerations. This result is in good agreement with Rickeard et al. (1996). The gasoline fuelled vehicle shows a different particle emission profile. Here, the particle emission was highest for all size channel during the cold start period. Even at the highest load only a moderate particle number was produced in the investigated size channels.

\section{Acknowledgements}

We would like to thank Anna-Maria Forss for the chemical analysis. This work has received financial support from the Association of Swiss Gas Industry and the Swiss Energy Agency.

\section{References}

Knutson, E. O. and Whitby, K. T. (1975) Aerosol Classification by Electric Mobility: Apparatus, Theory, and Applications. Aerosol Sci. 6, 443-451.

Rickeard, D. J., Bateman, J. R., Kwon, Y. K., McAughey, J. J., Dickens, C. J. (1996) Exhaust particulate size distribution: Vehicle and fuel influences in light duty vehicles. SAE961980.

Steiner, D. and Burtscher, H. (1993) Comparison of the sorption properties for PAH's of combustion particles with model particles. Water, Air, Soil Pollut. 68, 149-157. 